\title{
Opioid-induced Lower Esophageal Sphincter Dysfunction
}

\author{
Esteban Sáez González, ${ }^{1 *}$ Vicente Ortiz Bellver, ${ }^{1}$ Francia Carolina Díaz Jaime, ${ }^{1}$ Juan Antonio Ortuño Cortés, ${ }^{1}$ and \\ Vicente Garrigues $\mathrm{Gil}^{1,2}$
}

${ }^{1}$ Digestive Functional Disorders Unit, Gastroenterology Department, Hospital Universitari i Politècnic La Fe, Valencia, Spain and ${ }^{2}$ Department of Medicine, Universitat de Valencia, Valencia, Spain

The adverse gastrointestinal effects of opioids have been extensively described in medical literature. ${ }^{1}$ Their effect takes place mainly on the enteric nervous system, through receptors in the myenteric and submucosal plexuses. There are 3 recognized main opium receptors $(\mu, \delta$, and $\kappa)$ that are expressed in the central and enteric nervous systems, which mediate the gastrointestinal effects. ${ }^{2}$

The mainly studied adverse gastrointestinal effect of opioids is constipation, due to the greater understanding of opium receptor physiology in the colon. ${ }^{3}$ However their effect on esoph- ageal motility has seldom been studied.

Our study's objective was to assess esophageal motility, using high-resolution manometry (HRM), in patients undergoing long-term opioid therapy, referred for dysphagia study to the Digestive Functional Disorders Unit. A descriptive, prospective study of consecutive patients was conducted from January 2014 to May 2015. The clinical and manometric data of 5 patients with dysphagia undergoing opioid therapy were collected consecutively. In all cases, opioid therapy preceded the onset of dysphagia. There were no previous medical conditions that explained the

Table. High-resolution Manometric Findings in Patients With Opioid-induced Dysphagia

\begin{tabular}{|c|c|c|c|c|c|}
\hline Manometric data & $\begin{array}{c}\text { 4s-IRP } \\
(\mathrm{mmHg})^{\mathrm{a}}\end{array}$ & $\begin{array}{c}\text { Baseline LES pressure } \\
\text { (mmHg) }\end{array}$ & $\begin{array}{c}\text { DCI } \\
(\mathrm{mmHgsec} m)\end{array}$ & $\begin{array}{l}\text { Esophageal } \\
\text { aperistalsis }\end{array}$ & Manometric diagnosis \\
\hline Patient 1 & 21 & 32 & 7009 & YES & Type III achalasia \\
\hline Patient 2 & 20 & 50 & 3781 & NO & Functional EGJ obstruction \\
\hline Patient 3 & 10 & 30 & 1602 & $\mathrm{NO}$ & Functional EGJ obstruction \\
\hline Patient 4 & 13 & 55 & 1596 & $\mathrm{NO}$ & Functional EGJ obstruction \\
\hline Patient 5 & 8 & 37 & 134 & YES & Type III achalasia \\
\hline
\end{tabular}

${ }^{\mathrm{a}}$ Pathological 4s-IRP $>6.5 \mathrm{mmHg}\left(\right.$ adapted from Ortiz et $\left.\mathrm{al}^{4}\right)$.

4s-IRP, 4-second integrated relaxation pressure; LES, lower esophageal sphincter; DCI, distal contractile integral; EGJ, esophagogastric junction.

Received: June 19, 2015 Revised: July 8, 2015 Accepted: July 16, 2015

(c) This is an Open Access article distributed under the terms of the Creative Commons Attribution Non-Commercial License (http://creativecommons. org/licenses/by-nc/4.0) which permits unrestricted non-commercial use, distribution, and reproduction in any medium, provided the original work is properly cited.

${ }^{*}$ Correspondence: Esteban Sáez González, MD

Servicio de Medicina Digestiva, Hospital Universitari i Politècnic LA FE, Av. Fernando Abril, Martorell, 106, Valencia 46026, Spain Tel: +34-616124467, E-mail: esteban.digestivo@gmail.com

Financial support: None.

Conflicts of interest: None.

Author contributions: Vicente Ortiz, Esteban Sáez, Vicente Garrigues Gil Francia Carolina Díaz Jaime, and Juan Antonio Ortuño contributed to conception and design, analysis, and interpretation of data and Esteban Sáez González contributed to performed the research and wrote the manuscript.

ORCID: Vicente Ortiz, http://orcid.org/0000-0002-3237-9145. 
dysphagia, and all patients underwent upper endoscopy and biopsies, with normal results. The HRM studies were performed with the patient supine after an 8-hour fast, using equipment with perfused catheters, based on our unit's protocol. ${ }^{4}$ Manometric diagnosis was based on the international Chicago classification criteria. $^{5}$

The HRM showed lower esophageal sphincter (LES) hypertonia with pathological relaxation in all cases. Based on the
Chicago criteria, all 5 patients had esophageal motility disorders encompassed within the group called "motility disorders with esophagogastric junction (EGJ) outflow obstruction: Achalasia I, II, III, and functional EGJ obstruction." Two patients met the achalasia criteria and 3 for functional EGJ obstruction criteria (Table and Figure). Three of the 5 patients required pneumatic dilation due to the severity of dysphagia, with little improvement of symptoms. Opioid medication was not able to be withdrawn in

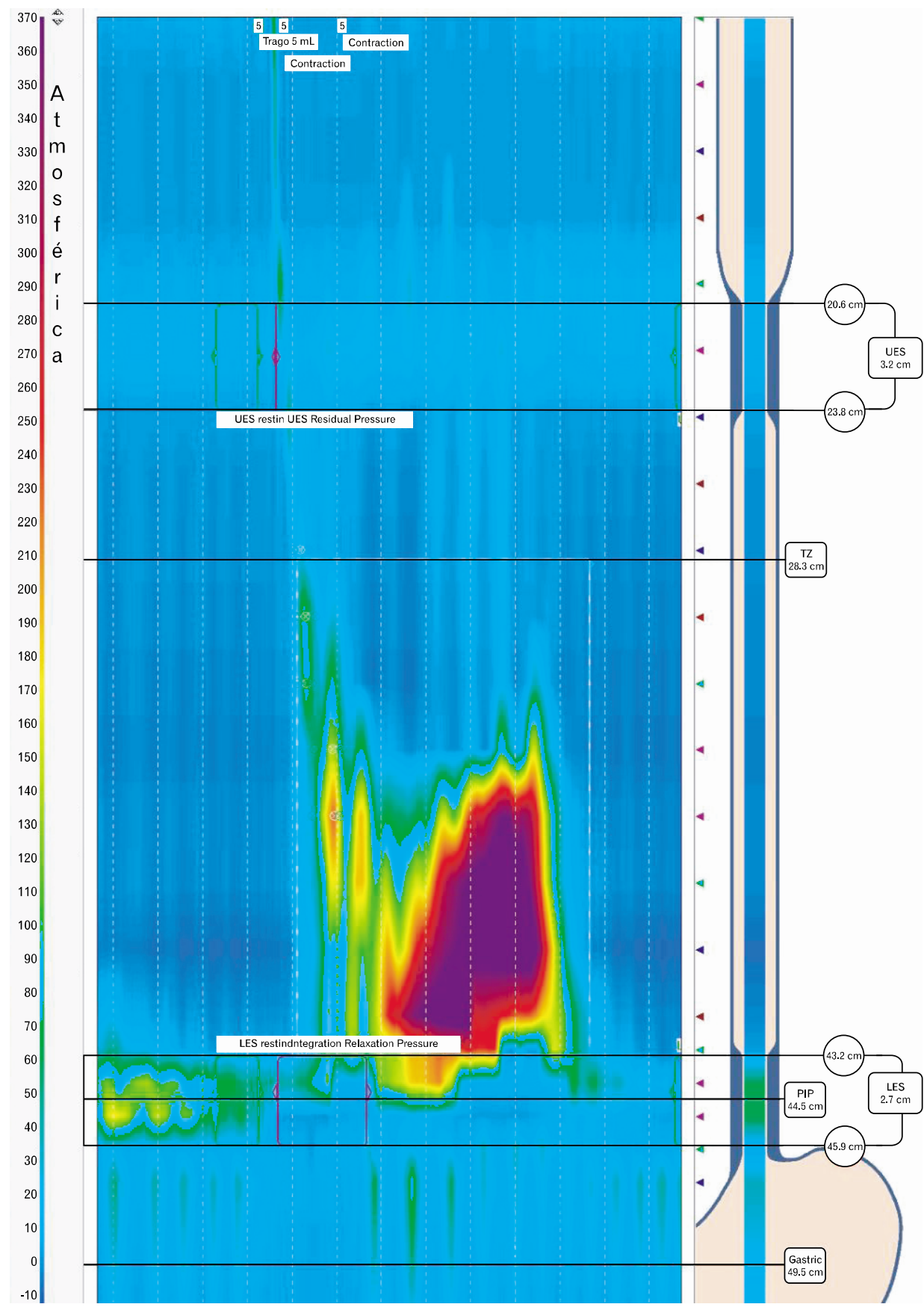

Figure. High-resolution manometric findings in a patient with opioid-induced dysphagia. Type III achalasia is seen. 
any of the cases.

The effect of opioids on esophageal motility has seldom been studied. Various studies with healthy volunteers have shown increased baseline LES pressure with incomplete relaxation when administering opioids. ${ }^{6,7}$ Kraichely et al $^{8}$ confirmed these findings in clinical practice in a retrospective study of 15 patients with dysphagia and opioid consumption when manometry was performed. Our study evaluated the esophageal motility of patients with dysphagia and opioid consumption using HRM.

The mechanism responsible for the effects of opioids on esophageal motility remains unclear; however, the nitric oxide pathway has been suggested to play an important role. ${ }^{8}$ Literature has shown that long-term opioid consumption can induce Oddi's sphincter dysfunction, causing its muscles to spasm, which could have interaction pathways similar to those in the esophagus.

Although clinical improvement with drugs and dilation is $>$ $50 \%$ in published studies on the therapeutic management of esophageal motility disorders, ${ }^{10}$ these treatments in patients having opioid-induced dysphagia resulted in little response. This fact and the onset of symptoms after starting opioid treatment support the relationship between these drugs and the onset of motility disorders.

In conclusion, long-term opioid use can induce esophageal motility disorders similar to achalasia or functional EGJ obstruction. These drugs should be considered in the differential diagnosis of processes that alter esophageal motility, mainly motor disorders which progress with pathological LES relaxation and sphincter hypertonia.

\section{References}

1. Dorn S, Lembo A, Cremonini F. Opioid-induced bowel dysfunction: Epidemiology, pathophysiology, diagnosis and initial therapeutic approach. Am J Gastroenterol 2014;2:31-37

2. Wood JD, Galligan JJ. Function of opioids in the enteric nervous system. Neurogastroenterol Motil 2004;16(suppl 2):17-28.

3. Camilleri M. Opioid-induced constipation: challenges and therapeutic opportunities. Am J Gastroenterol 2011;106:835-842.

4. Ortiz V, Poppele G, Alonso N, Castellano C, Garrigues V. Evaluation of esophagogastric junction relaxation by 4-second integrated relaxation pressure in achalasia using high resolution manometry with water-perfused catheters. Neurogastroenterol Motil 2014;26:15511556.

5. Kahrilas PJ, Bredenoord AJ, Fox M, et al. The Chicago classification of esophageal motility disorders, v3.0. Neurogastroenterol Motil 2015;27:160-174.

6. Dowlatshahi K, Evander A, Walther B, Skinner DB. Influence of morphine on the distal oesophagus and the lower oesophageal sphincter--a manometric study. Gut 1985;26:802-806.

7. Penagini R, Picone A, Bianchi PA. Effect of morphine and naloxone on motor response of the human esophagus to swallowing and distension. Am J Physiol 1996;271(4 Pt 1):G675-G680.

8. Kraichely RE, Arora AS, Murray JA. Opiate-induced oesophageal dysmotility. Aliment Pharmacol Ther 2010;31:601-606.

9. Wu SD, Zhang ZH, Jin JZ, et al. Effects of narcotic analgesic drugs on human Oddi's sphincter motility. World J Gastroenterol 2004;10: 2901-2904

10. Vaezi MF, Pandolfino JE, Vela MF. ACG clinical guideline: diagnosis and management of achalasia. Am J Gastroenterol 2013;108: 1238-1249. 